\title{
Justicia como memoria y derecho a la verdad frente a la política de silencio y olvido en El Salvador: Apuntes sobre la percepción de la figura de Óscar Arnulfo Romero y la experiencia de los diálogos intergeneracionales en las parroquias de la Arquidiócesis de San Salvador*
}

\author{
Justice as Memory and Right to the Truth Versus the \\ Policy of Silence and Oblivion in El Salvador: Notes \\ on the Public Perception of Oscar Arnulfo Romero \\ and the Experience of Intergenerational Dialogues in \\ the Parishes of the Archdiocese of San Salvador \\ Justiça como memória e direito à verdade frente à \\ política de silêncio e esquecimento em El Salvador: \\ Apontes sobre a percepção da figura de Oscar \\ Arnulfo Romero e a experiência dos diálogos entre \\ gerações nas paróquias da Arquidioceses de San \\ Salvador
}

Héctor Olasolo

\begin{abstract}
El presente trabajo hace parte del proyecto de investigación Principios de armonización entre la función y alcance de la justicia y las demandas suróidas en los procesos políticos de transición, que se encuentra adscrito a la línea de investigación Crítica al derecho internacional desde fundamentos filosóficos, del Grupo de Investigación de Derecho Internacional de la Facultad de Jurisprudencia de la Universidad del Rosario, Bogotá, Colombia. El proyecto es financiado por la Dirección de Investigación e Innovación de la Universidad del Rosario. El autor agradece al Padre Luciano Ernesto Pérez Reyes García (director adjunto de la Oficina de Tutela de Derechos Humanos del Arzobispado de San Salvador), al abogado Roberto Carlos Alfaro Lara y a los demás integrantes del equipo de trabajo de la Oficina de Tutela de Derechos Humanos en las áreas jurídica, educativa y de archivo histórico, por la fraterna acogida recibida durante la visita del mes de julio de 2018 y el acceso irrestricto a los materiales contenidos en el archivo histórico. El autor también agradece al profesor de teoría del Derecho en la Universidad de El Salvador, el licenciado José Miguuel Vásquez López, y a su entonces monitor, el Sr. Enmanuel Cristóbal Román Funes, por su excelente acoģida en 2017 su curso de teoría del Derecho, así como a la joven investigadora de la Universidad del Rosario (Colombia), Lucia Cárcano Fernández, por su trabajo de investigación en relación con la jurisprudencia del Sistema Inter-Americano de Derechos Humanos sobre los distintos componentes del derecho a la verdad de las víctimas de graves violaciones de derechos humanos.
\end{abstract}




\section{Resumen}

La política de silencio y olvido, que fue adoptada en El Salvador tras la Ley de Amnistía de 1993, ha fomentado el desconocimiento en la sociedad salvadoreña (particularmente en los jóvenes menores de veinticinco años) sobre las causas y consecuencias del conflicto armado no internacional que tuvo lugar entre 1980 y 1992, y sobre las graves violaciones de Derechos Humanos que ocurrieron en el mismo. Las parroquias de la Iglesia salvadoreña no son ajenas a esta situación porque, como han puesto de manifiesto los diálogos intergeneracionales promovidos desde la Oficina de Tutela de Derechos Humanos del Arzobispado de San Salvador en julio de 2018, sus integrantes más jóvenes desconocen completamente el grado de persecución al que sus hermanos de comunidad fueron sometidos durante el conflicto armado por las fuerzas militares y policiales. La controversia que ha existido, al menos hasta 2013, entre diversos sectores de la Iglesia salvadoreña sobre la figura de Óscar Arnulfo Romero es fruto de esta situación, que afecta las dimensiones individual y colectiva del derecho a la verdad, impide la satisfacción de la justicia entendida como memoria, evita que los graves crímenes internacionales cometidos en El Salvador sean tenidos en cuenta a la hora de construir su memoria histórica, ofrece un caldo de cultivo favorable al revisionismo histórico e impide que

** Licenciado y doctor en Derecho por la Universidad de Salamanca (España). Magíster en Derecho por la Universidad de Columbia (EE. UU). El profesor Olasolo es actualmente catedrático de Derecho internacional en la Universidad del Rosario (Colombia), donde dirige los programas de Maestría y Especialización en Derecho Internacional, su Clínica Jurídica Internacional y el Anuario Iberoamericano de Derecho Internacional Penal (ANIDIP). Es profesor ad hoc de la Universidad de La Haya para las Ciencias Aplicadas (Holanda) y preside desde 2011 el Instituto Ibero-Americano de la Haya para la Paz, los Derechos Humanos y la Justicia Internacional (Holanda). Además, se ha desempeñado como catedrático de Derecho Internacional Penal en la Universidad de Utrecht (Holanda, 2010-2012), maģistrado auxiliar de la Corte Penal Internacional (2004-2010), miembro de la Fiscalía del Tribunal Internacional Penal para la ex Yugoslavia (2002-2004) y asesor jurídico de la deleģación española en la Comisión Preparatoria de la Corte Penal Internacional (1999-2002). Ha sido también asesor externo del Tribunal Especial para el Líbano, miembro del Roster de Juristas de Reconocido Prestigio de la Orģanización de las Naciones Unidas para el Nombramiento de Maģistrados Internacionales en las Salas Especiales de los Tribunales de Camboya, perito ante la Corte Inter-Americana de Derechos Humanos. 
se puedan adoptar las medidas necesarias para evitar su repetición. Frente a esta situación, los diálogos intergeneracionales celebrados en 2018 en algunas parroquias de la Arquidiócesis de San Salvador han mostrado su capacidad para exponer y superar el impacto negativo de la política del silencio y el olvido desde las propias comunidades parroquiales afectadas.

Palabras Clave: amnistía, política de silencio y olvido, derecho a la verdad, justicia anamnética, derecho a la reparación, garantías de no repetición, memoria, El Salvador, Oscar Arnulfo Romero, diálogos intergeneracionales

\section{Abstract}

The policy of silence and oblivion, adopted in El Salvador after the 1993 Amnesty Law, has fostered ignorance in Salvadoran society (particularly in young people under twenty-five) about the causes and consequences of the 1980-1992 non-international armed conflict and about the critical human rights violations that occurred in it. The parishes of the Salvadoran church are not alien to this situation; as the intergenerational dialogues promoted by the Office of Tutela de Derechos Humanos of the Archbishopric of San Salvador in July 2018 have shown, their younger members are unaware of the military and police forces persecutions to their community during the armed conflict. The controversy over Oscar Arnulfo Romero, at least until 2013, between different Salvadoran church factions is the result of that situation, which negatively affects the individual and collective right to the truth extents. Additionally, it prevents the satisfaction of justice (understood as memory), considering the serious international crimes committed in El Salvador when constructing its historical memory and taking the necessary measures to avoid new critical human rights violations. Finally, it provides a breeding ground for historical revisionism. Faced with this situation, the intergenerational dialogues held in 2018 in some parishes of the Archdiocese of San Salvador have shown their ability to expose and overcome the negative impact of the policy of silence and oblivion.

\section{Keywords: Amnesty, policy of silence and oblivion, right to the truth, anamnestic justice, right to reparation, guarantees of non-repetition, historical memory, El Salvador, Oscar Arnulfo Romero, intergenerational dialogues.}

\section{Resumo}

A política de silêncio e esquecimento, que foi adotada em El Salvador após a Lei de Amnistia de 1993, tem fomentado o desconhecimento na sociedade salvadorenha (particularmente nos jovens menores de vinte e cinco anos) sobre as causas e consequências do conflito armado não internacional que aconteceu entre 1980 
e 1992, e sobre as graves violações de direitos humanos que aconteceram nele. As paróquias da Igreja salvadorenha não são alheias a esta situação porque, como têm manifestado os diálogos entre gerações promovidos desde o Escritório de Tutela de Direitos Humanos do Arcebispado de San Salvador em julho de 2018, suas integrantes mais jovens desconhecem completamente o grau de persecução ao que seus irmãos de comunidade foram submetidos durante o conflito armado pelas forças armadas e policiais. A controvérsia que tem existido, pelo menos até 2013, entre diversos setores da Igreja salvadorenha sobre a figura de Oscar Arnulfo Romero é resultado desta situação, que afeta às dimensões individual e coletiva do direito à verdade, impede a satisfação da justiça percebida como memória, evita que os graves crimes internacionais cometidos em El Salvador sejam tidos em conta no momento de construir sua memória histórica, oferece um caldo de cultivo favorável ao revisionismo histórico e impede que se podam adotar as medidas necessárias para evitar sua repetição. Frente a esta situação, os diálogos entre gerações celebrados em 2018 em algumas paróquias da Arquidiocese de San Salvador têm mostrado sua capacidade para expor e superar o impacto negativo da política do silêncio e o esquecimento desde as próprias comunidades paroquiais afetadas.

Palavras-chave: amnistia, política de silêncio e esquecimento, direito à verdade, justiça anamnéstica, direito à reparação, garantias de não repetição, memória,

El Salvador, Oscar Arnulfo Romero, diálogos entre gerações

\section{Introducción: primera aproximación al impacto de la política del silencio y el olvido en El Salvador}

Todas las mañanas tengo la costumbre de salir a caminar. Sin embargo, nunca había valorado tanto la posibilidad de pasear hasta mi reciente visita en julio de 2018 al archivo de la Oficina de Tutela de Derechos Humanos del Arzobispado de San Salvador. La razón no es otra que las dificultades con las que me encontré para poder llegar caminando hasta allí desde el apartamento en que me alojaba en la colonia Miramonte. Aunque haciendo gala de una exquisita amabilidad cada día me recogieron para llevarme en coche hasta el trabajo, la opción de caminar ni siquiera estuvo sujeta a discusión, porque pasear es demasiado peligroso en una sociedad donde los seres humanos viven poco menos que enjaulados en perímetros de cuatro o cinco manzanas a la redonda controlados por distintos grupos armados al margen de la ley (el que se denomine a estos grupos pandillas porque están principalmente formados por jóvenes menores de 15 años no les priva de dicha naturaleza). 
Salir del área donde se tiene el domicilio que aparece reflejado en el Documento Único de Identidad (DUI) significa jugarse la vida en caso de ser interceptado por una pandilla enemiga que controla la zona por la que se transita, y cuyos miembros pueden verificar la dirección de residencia mediante una rápida revisión del DUI (no llevarlo o negarse a mostrarlo significa asumir el riesgo de sufrir una muerte violenta). Consecuencia de lo anterior, durante una visita realizada en 2017 al curso de teoría jurídica de la licenciatura en Derecho de la Universidad de El Salvador, uno de cada cinco estudiantes del curso contestó afirmativamente a la pregunta sobre si habían recibido alguna vez amenazas de muerte. Según explicaron los interesados, caminar para asistir a clase por sectores que no son los propios hace que estas situaciones sean bastante comunes. La situación no es mejor si se suben a los autobuses que transitan a través de sectores controlados por las pandillas, donde los hurtos son cotidianos y los episodios de desaparición forzada (tras obligar a los pasajeros a bajarse) son frecuentes. El propio monitor del curso afirmó cómo, gracias a un compañero de secundaria, había salvado su vida cuando acudió a solicitar un certificado de estudios a su antiguo instituto, que se encontraba ubicado en un sector distinto a aquel al que sus padres habían trasladado recientemente su domicilio.

Pero si el desplazamiento a pie o en autobús desde una colonia a otra de San Salvador (o incluso entre sectores de una misma colonia controlados por distintas pandillas) conlleva los riesgos mencionados, el recorrido intelectual y espiritual al encuentro del pasado reciente no resulta menos amenazador. La política oficial de silencio y olvido en la que fue sumida la sociedad salvadoreña tras la Ley de Amnistía de 1993 -que fue aprobada cinco días después de los señalamientos realizados a diversas autoridades militares y policiales en el informe publicado el 15 de marzo de 1993 por la Comisión de la Verdad de El Salvador bajo el título De la locura a la esperanza: la guerra de 12 años en El Salvador- ha fomentado el desconocimiento por aquella parte de la población salvadoreña que no vivió el conflicto armado (en particular, quienes cuentan en la actualidad con menos de veinticinco años), lo que favorece el revisionismo histórico e impide la adopción de las medidas necesarias para evitar su repetición.

Un buen ejemplo del impacto negativo provocado por esta política lo pude experimentar al día siguiente de mi llegada a San Salvador, cuando seguí por televisión un debate sobre la memoria histórica del conflicto armado ocurrido entre 1980 y 1992. Me llamó la atención la afirmación de algunos de los panelistas, todos ellos conocidos actores en la vida pública salvadoreña, sobre la presunta tendencia de izquierdas de los integrantes de la Comisión de la Verdad, lo que, en su opinión, explicaría el contenido sesgado del Anexo a su informe, en el que se afirmaba que 
de las 14.000 denuncias recibidas en el periodo de seis meses en el que desarrolló sus actividades, el $85 \%$ tuvieron como objeto hechos presuntamente cometidos por agentes del Estado, el $10 \%$ por integrantes de los escuadrones de la muerte y el $5 \%$ por miembros de las cinco organizaciones que conformaban el Frente Farabundo Martí para la Liberación Nacional (FMLN).

En vista de lo afirmado, hice una rápida búsqueda en Internet mientras seguía el debate para confirmar el nombre y la trayectoria profesional de los miembros de la Comisión, con el fin de determinar el grado de verosimilitud de los argumentos que estaban siendo esgrimidos. Mi sorpresa no pudo ser mayor al observar que su presidente había sido el Sr. Belisario Betancourt, dirigente del Partido Conservador en Colombia y presidente de este país entre 1982 y 1986. Así mismo, fungió como miembro adjunto de la Comisión en apoyo de su presidente el Sr. Guillermo Fernández de Soto, quien, además de ocupar entre 1998 y 2002 la posición de canciller en el gobierno de Andrés Pastrana (último presidente del Partido Conservador que ha tenido Colombia), estuvo a cargo de las negociaciones del Plan Colombia con los EE.UU. Con independencia de la calidad profesional de los mencionados integrantes de la Comisión, no cabe duda de que ninguno de los dos puede ser catalogado como un referente de la izquierda latinoamericana de finales del siglo XX y principios del siglo XXI.

Infortunadamente, la confusión a la que varios de los panelistas trataban de inducir a los telespectadores salvadoreños sólo puede lograr su objetivo en el caldo de cultivo del desconocimiento general provocado por la política de silencio y olvido que se implantó en la sociedad salvadoreña a raíz de la Ley de Amnistía de 1993.

Los miembros de las comunidades parroquiales de la Iglesia Católica salvadoreña ("la Iglesia", "la Iglesia de El Salvador" o "la Iglesia salvadoreña") tampoco son ajenos a esta situación, de manera que sus integrantes más jóvenes desconocen completamente el grado de persecución al que fueron sometidos los integrantes de numerosas comunidades católicas (especialmente, en la Arquidiócesis de San Salvador) por las fuerzas militares y policiales. Según se afirma por el Secretariado Social Interdiocesano (1977):

El documento que presentamos ha surgido de la necesidad de esclarecer la actual situación del país y más en concreto de la Iglesia de la Arquidiócesis de San Salvador en ese contexto general. Que los hechos de violencia abundan en nuestro país es una realidad que desgraciadamente todos reconocen. Que esos hechos sean también "persecución a la Iglesia" es afirmado claramente por la Jerarquía, 
clero y la inmensa mayoría de los cristianos (p. 3)[...] La Iglesia de la Arquidiócesis afirma, por tanto que, aunque según la legalidad vigente, existe libertad de religión y de culto y reconocimiento jurídico de la Iglesia, sus personas e instituciones, existe una persecución contra ella a través de las campañas de prensa y de hechos físicos violentos porque se le está impidiendo eficazmente, a través de la inutilización de sus agentes misioneros, llevar a cabo su misión (p. 5)[...] Hasta hace unos meses no se ha hablado de persecución en la Iglesia de El Salvador. Lo que ha hecho que la situación actual de la Iglesia haya pasado a ser definida como situación de persecución es la serie ya muy numerosa de ataques - verbales o de hecho - contra miembros de la Jerarquía, contra miembros del clero y contra laicos explícitamente comprometidos en la tarea de evangelización. Se han dado también expresiones concretas de odio a la Iglesia y a sus símbolos tradicionales más venerados, sobre todo la Eucaristía (p. 7).

El Secretariado Social Interdiocesano (2005) subraya también el negacionismo de ciertos grupos sociales y afirma la necesidad de terminar con los intentos de imponer el silencio y el olvido. Según se menciona expresamente, “[...] Otros grupos sociales, los poderosos en general, niegan la tal persecución. En esta situación es un derecho de la Iglesia afirmar que existe persecución y es una urgente obligación pastoral esclarecer ante el pueblo cristiano y ante todo los hombres de buena voluntad en qué consiste la persecución y porqué se la puede denominar como tal" (p. 3).

Desgraciadamente, como muestra el contenido de los argumentos presentados por algunos de los panelistas en el debate arriba mencionado, y como han reflejado también las primeras experiencias de diálogo intergeneracional celebrados en julio de 2018 en varias parroquias de la Arquidiócesis de San Salvador, la aplicación de la Ley de Amnistía acabó siendo desarrollada por una férrea política de silencio y olvido.

Ante esta situación, analizamos en las próximas secciones el concepto de justicia como memoria y el contenido del derecho a la verdad de las víctimas de graves violaciones de Derechos Humanos (sección 2), el impacto de la política de silencio y olvido en la controvertida percepción de la figura de Óscar Arnulfo Romero en distintos sectores de la Iglesia salvadoreña (sección 3) y la experiencia de los diálogos intergeneracionales en las parroquias de la Arquidiócesis de San Salvador como herramienta para exponer y superar el impacto de la política de silencio y olvido (sección 4). El texto finaliza con una breve exposición de las principales conclusiones alcanzadas (sección 5). 


\section{La justicia como memoria y el derecho a la}

\section{verdad de las víctimas de graves violaciones}

\section{de Derechos Humanos}

El concepto de justicia como memoria encuentra sus raíces en un grupo de filósofos de finales del siglo XIX y principios del siglo XX (Cohen, Buber, Rosenzweig y Kafka) que, con base en sus orígenes judíos, pudieron anticipar la marginalidad, exclusión y exilio que sufrirían décadas después los pensadores que les sucedieron en la denominada Escuela de Frankfurt (Benjamin, Adorno y Horkhaimer). De todos ellos, Benjamin (2005) es quien nos ha dejado a través de su alegoría del ángel caído de la historia un concepto más elaborado de la justicia como memoria, entendida como una mirada al pasado que trata de atribuir sentido a lo que hasta entonces es considerado como despojo y olvido.

Para Benjamín (2005.), el sufrimiento y sinsentido de las vidas de las víctimas se convierte en el objeto central de la justicia, que se dirige a reavivar, desde la re-evaluación del pasado, la esperanza frente al olvido de quienes han sido condenados por la historia oficial de los vencedores. Con ello, como el propio Adorno (2006) subraya, se busca promover que las víctimas puedan reconstruirse del daño sufrido, superando con ello, si bien no olvidando (Levi, 2005), la propia condición de víctima en la que les ha colocado la historia (Berón Ospina, 2019).

En la aplicación del concepto de justicia como memoria, y a diferencia de lo que ha sucedido durante décadas en El Salvador, desde comienzos del siglo XXI se han puesto en marcha en Colombia iniciativas de memoria histórica caracterizadas por dos factores: (i) su simultaneidad con los procesos derivados de la Ley de Justicia y Paz (2005), la Ley de Víctimas (2011) y los Acuerdos de Paz con las Fuerzas Armadas Revolucionarias de Colombia ("FARC”) (2016); y (ii) su desarrollo en condiciones de permanente conflicto y desconfianza por las consecuencias que pueden generar (Berón Ospina, 2019).

De esta manera, ante la tensión entre las posiciones de Nietzsche (2015), quien ante las demandas de justicia de las víctimas afirma la necesidad de superar el recuerdo de un pasado que genera más dolor y resentimiento, y Benjamín (2005), que resalta la importancia de revisar lo que la memoria del vencedor oculta y justifica en detrimento del vencido, en El Salvador se ha adoptado el planteamiento del primero, mientras que en Colombia se está tratando de seguir, con grandes dificultades, la senda del segundo.

Estrechamente relacionado con el concepto de justicia como memoria, se encuentra el derecho a la verdad, que si bien inicialmente surgió en relación con las 
víctimas de desaparición forzada de la década de 1970, su ámbito de aplicación se ha extendido a las demás violaciones graves de Derechos Humanos, constituyendo en la actualidad uno de los derechos más relevantes, tanto en los procesos de transición, como a la hora de reparar las violaciones graves de Derechos Humanos (Ibáñez, 2014).

A nivel internacional, el desarrollo más completo del derecho a la verdad se encuentra en la interpretación jurisprudencial que los órganos del sistema interamericano de protección de Derechos Humanos han realizado de los artículos 8 y 25 de la Convención Americana sobre Derechos Humanos (CADH). ${ }^{1}$ Así, desde su primer caso, la Corte Interamericana de Derechos Humanos (a partir de ahora Corte IDH) ha afirmado el deber de los Estados de investigar la comisión de graves violaciones de Derechos Humanos. Además, en los casos de desaparición forzada, la Corte IDH ha subrayado también la obligación de los Estados de informar a los familiares de las víctimas sobre su paradero, o, en caso de fallecimiento, sobre el lugar en que se encontraban sus restos (Corte IDH, Velásquez Rodríguez, 1988).

Posteriormente, la Corte IDH ha señalado que el derecho a la verdad tiene también una dimensión colectiva, en la medida en que la sociedad tiene el derecho a conocer las circunstancias en que se han llevado a cabo las violaciones graves de Derechos Humanos (caso Barrios Altos, 2001), para tenerlas en cuenta al forjar su legado como nación, prevenir los procesos de revisionismo histórico y evitar su repetición (Szablewska \& Bachmann, 2015).

Además, la Corte IDH ha hecho énfasis en que el derecho a la verdad constituye una medida de reparación adecuada si se investigan los hechos del caso con el fin de identificar, juzgar y castigar a los responsables y, siempre y cuando, los resultados de la investigación se hagan públicos para que la sociedad conozca la verdad (caso Tibi, 2004). Con ello, la Corte IDH ha reconoció que, además de sus dimensiones individual y colectiva, el derecho a la verdad constituye también una forma de reparación (caso Comunidad Moiwana, 2005).

De esta manera, la Corte IDH ha acogido expresamente los distintos componentes del derecho a la verdad que la propia Comisión Interamericana de Derechos Humanos (“Com. IDH”) había desarrollado en los casos relativos a Parada Cea y otros (1999), Ignacio Ellacuría y otros (1999) y Monseñor Oscar Romero (2000), donde puesto que considera que, en última instancia, el no respetar este derecho constituye un trato inhumano o degradante para los familiares de las personas desaparecidas (caso Ipek c. Turquía, 2004). Sin embarơo, el TEDH no ha profundizado más en el contenido del derecho a la verdad, porque considera que se subsume en el derecho más amplio a un juicio justo e imparcial (caso Vanava et al. c. Turquía, 2009). 
la Com. IDH subrayó en particular que el conocimiento de las circunstancias de la violación constituye una medida de satisfacción y una garantía de no repetición. Esta última constituye a su vez un objetivo central de todo proceso de justicia de transición (Galain Palermo, 2016).

\section{La controversia sobre la percepción de la figura de Óscar Arnulfo Romero}

A pesar de la importancia para las víctimas de graves violaciones de Derechos Humanos de la justicia como memoria y del derecho a la verdad, lo cierto es que el desconocimiento generado por la política de silencio y olvido en El Salvador ha llegado durante mucho tiempo incluso a alcanzar a la figura del primer santo de su Iglesia, Óscar Arnulfo Romero, quien el 24 de marzo de 1980 cayó abatido por un francotirador perteneciente a los escuadrones de la muerte mientras celebraba misa en la capilla del Hospital de la Divina Providencia.

Su muerte se producía al mes siguiente de haber escrito en su condición de arzobispo de San Salvador al presidente de los EE.UU., Jimmy Carter, solicitándole que cancelase toda la ayuda militar al gobierno salvadoreño porque con ella estaba fortaleciendo un régimen opresor (la existencia de esta carta fue rebelada por el propio Romero en su homilía de 16 de marzo de 1980) (Tamayo, 2015). Así mismo, el día anterior a su asesinato, denunciaba de nuevo en la catedral de San Salvador la cruel represión que llevaban a cabo las fuerzas y cuerpos de seguridad del Estado salvadoreño, y recordaba a sus miembros que, por encima de las órdenes de matar, se encontraba el mandato divino de no matarás:

Yo quisiera hacer un llamamiento de manera especial a los hombres del Ejército, y en concreto a las bases de la Guardia Nacional, de la policía, de los cuarteles. Hermanos, son de nuestro mismo pueblo, matan a sus mismos hermanos campesinos y, ante una orden de matar que dé un hombre, debe de prevalecer la ley de Dios que dice: "No matar". Ningún soldado está obligado a obedecer una orden contra la ley de Dios. Una ley inmoral, nadie tiene que cumplirla. Ya es tiempo de que recuperen su conciencia y que obedezcan antes a su conciencia que a la orden del pecado. La Iglesia, defensora de los derechos de Dios, de la ley de Dios, de la dignidad humana, de la persona, no puede quedarse callada ante tanta abominación. Queremos que el Gobierno tome en serio que de nada sirven las reformas si van teñidas con tanta sangre. En nombre de Dios, pues, y en nombre de 
este sufrido pueblo, cuyos lamentos suben hasta el cielo cada día más tumultuosos, les suplico, les ruego, les ordeno en nombre de Dios: ¡cese la represión! (Romero, 2005, Vol. VI).

De esta manera, en el ámbito de su competencia pastoral, Romero se hacía eco del principio 4 de los Principios de Derecho Internacional reconocidos por el Estatuto (1945) y la sentencia del Tribunal Militar Internacional con sede en Núremberg (1946), y sistematizados por la Comisión de Derecho Internacional (1950), conforme al cual, [e]l hecho de que una persona haya actuado en cumplimiento de una orden de su Gobierno o de un superior jerárquico no la exime de responsabilidad conforme al derecho internacional, si efectivamente ha tenido la posibilidad moral de opción. ${ }^{2}$

A pesar de las numerosas voces que solicitaron desde su asesinato la beatificación y canonización de Romero, durante años no fue posible avanzar en el procedimiento (Ordaz, 2015; Europa Press, 2015), de manera que sólo en 2015 fue declarado beato, convirtiéndose tres años después, el 14 de octubre de 2018, en el primer santo de la Iglesia de El Salvador (Lima, 2018).

Pero, ¿por qué fueron necesarios treinta y cinco años? La razón es que una parte importante de la Iglesia institucional salvadoreña y de sus comunidades no veían en Romero la figura del mártir de los pobres, sino la de un colaboracionista con los movimientos políticos y sindicales, que meses después de su muerte se articularían en el FMLN para sostener un cruento conflicto civil con las fuerzas gubernamentales, que se extendería hasta los acuerdos de paz firmados en el Castillo de Chapultepec (México D.C.) el 16 de enero de 1992.

Esta división en la percepción del papel jugado por Romero, que ha traspasado las fronteras de El Salvador para llegar incluso a Roma (Ordaz, 2015; Europa Press, 2015), se recoge en toda su crudeza en el resumen de prensa anexado al mencionado trabajo del Secretariado Social Interdiocesano (1977), que fue recopilado apenas ocho meses después del nombramiento de Romero como arzobispo de San Salvador. Dicho resumen de prensa recoge desde manifiestos de ciertos grupos

2 Casi veinte años después del asesinato de Romero, el art. 33 (1) del Estatuto de la Corte Penal Internacional (ECPI), aprobado en 1998 y en vigor desde 2002, desarrollaría este mismo principio al establecer que "[q]uien hubiere cometido un crimen de la competencia de la Corte en cumplimiento de una orden emitida por un ģobierno o un superior, sea militar o civil, no será eximido de responsabilidad penal a menos que: a) [e]stuviere obliģado por ley a obedecer órdenes emitidas por el gobierno o el superior de que se trate; b) [n]o supiera que la orden era ilícita; y c) [l]a orden no fuera manifiestamente ilícita". Además, el párrafo 2 del propio art. 33 del ECPI añadía que "[a] los efectos del presente artículo, se entenderá que las órdenes de cometer genocidio o crímenes de lesa humanidad son manifiestamente ilícitas". En consecuencia, las órdenes de matar, como aquellas a las que se refirió Romero en su homilía de 23 de marzo de 1980, no son susceptibles, bajo ninģuna circunstancia, de eximir de responsabilidad a quienes las llevan a cabo, porque, al ser constitutivas de crímenes de lesa humanidad, se presume iure et de iure que son manifiestamente ilícitas. 
autodenominados Sociedad Cristiana Salvadoreña, Asociaciones Católicas y Evangélicas de El Salvador, Comité Pro-mejoramiento de la Iglesia Católica y Auténticos Demócratas Cristianos (por poner sólo algunos ejemplos), hasta artículos y columnas de opinión de los diarios más importantes de El Salvador en aquel momento, como La Prensa Gráfica y El Diario de Hoy, pasando por declaraciones de entidades económicas de la relevancia de la Asociación Nacional de la Empresa Privada (ANEP) y del Frente Agropecuario de la Región Oriental (FARO).

Los manifiestos, artículos y columnas de opinión contenidos en este anexo se caracterizan por presentar duras críticas a la gestión de Romero por su omisión en tomar las medidas necesarias para que muchos de sus sacerdotes dejasen de seguir sembrando violencia y propiciando el derramamiento de sangre. Además, con frecuencia se incluyen ataques personales contra la figura de Romero por "[...] no querer ver las culpas de esos curas malos y, en cambio, para el son culpables quienes los censuran, quienes denuncian sus fechorías, quienes desean la depuración del clero a fin de que nuestra Iglesia católica se mantenga impoluta y reverenciada".

De esta manera, y salvando las distancias, la situación de Romero durante su mandato como arzobispo de San Salvador presentaba notables similitudes con la descrita en los inmortales versos de Antonio Machado (1971):

\author{
Ya hay un español que quiere \\ vivir y a vivir empieza, \\ entre una España que muere \\ y otra España que bosteza.
}

\author{
Españolito que vienes \\ al mundo te guarde Dios, \\ una de las dos Españas \\ ha de helarte el corazón.
}

Tras su muerte, una parte importante de la Iglesia institucional salvadoreña y de sus fieles continuaron considerando que Romero se apartó de la ortodoxia de los sectores más conservadores a los que había pertenecido hasta su nombramiento como arzobispo de San Salvador el 8 de febrero de 1977 (y a los que, en gran medida, debía dicho nombramiento) (Lima, 2018), como consecuencia del impacto emocional que le causó el asesinato el 12 de marzo de ese mismo año del sacerdote jesuita Rutilio Grande, con quien le unía una relación muy cercana desde su paso por el seminario hacía casi cuarenta años (Cardenal, 2015). Según este sector, antes 
de este giro, Romero se había mostrado crítico con los nuevos caminos abiertos por el Concilio Vaticano II (1962-1965), había cambiado la línea editorial del semanario Orientación, se había manifestado contra ciertas prácticas del Externado de San José en San Salvador, la Universidad Centroamericana (“UCA") y otras instituciones educativas dirigidas por los jesuitas, y había contribuido en 1972 a apartar a estos últimos de la formación de seminaristas, lo que, una vez nombrado Secretario de la Conferencia Episcopal Salvadoreña en 1967 y Obispo Auxiliar de San Salvador en 1970, deterioró sus relaciones con el entonces arzobispo Chávez y González, y con el segundo obispo auxiliar Rivera y Damas.

Un segundo sector de la Iglesia institucional salvadoreña y de sus fieles, que se encontraban en buena medida en la Arquidiócesis de San Salvador, mantuvieron tras la muerte de Romero una percepción muy distinta de los aspectos de su vida arriba mencionados. Para este sector, Romero fue siempre sensible al sufrimiento de amplias capas de la población por sus paupérrimas condiciones materiales de vida como consecuencia de su formación con los jesuitas en el Colegio Pío Latino Americano de Roma y su estrecha relación con algunos miembros de esta comunidad (incluyendo a Grande), que trataban de buscar herramientas para mejorar las condiciones socio-económicas de los sectores más desfavorecidos mediante el fortalecimiento de su nivel de asociacionismo y el consiguiente incremento de su capacidad de negociación. Además, si bien de una manera más discreta, Romero siempre se preocupó por los casos de represión de campesinos y trabajadores por las fuerzas militares y de policía, así como por los grupos irregulares con quienes aquellas colaboraban, lo que se tradujo en solicitudes de investigación realizadas por carta o a través de entrevistas privadas con las autoridades competentes. Este fue, por tanto, el caldo de cultivo que propició que las traumáticas experiencias vividas durante el primer mes de su mandato como arzobispo de San Salvador, le llevasen a adoptar una posición más pública de denuncia de la represión (así como de la violencia revolucionaria) y a volcar sus tres últimos años de vida al acompañamiento y asistencia a los más desfavorecidos (lo que en última instancia le granjeó el calificativo de mártir de los pobres) (Brockman, 1985; Cavada, 2005; Delgado Acevedo, 1985; López Vigil, 1993; Mata, 2015; Morozzo della Rocca, 2010). ${ }^{3}$

3 Quienes defienden esta posición no ven en el asesinato de Grande la razón que le llevó a presentar con mayor publicidad sus denuncias, sino que lo ven como un proceso más progresivo, que tuvo mucho que ver con la exposición pública al que lo llevó su nueva posición como arzobispo de San Salvador y la situación de tensión allí vivida días después de asumir su mandato como resultado del fraude electoral ocurrido en las elecciones presidenciales de 20 de febrero de 1977, y la convocatoria por sindicatos y partidos de izquierda de manifestaciones multitudinarias y de un campamento en la plaza de la Libertad a escasos 200 metros de la catedral de San Salvador. En particular, quienes defienden esta segunda posición subrayan que, al autorizar 
Con independencia de cual de las dos visiones de la figura de Romero se acercaba más a la realidad, lo cierto es que la política de silencio y olvido adoptada en El Salvador tras la Ley de Amnistía de 1993 constituyó durante dos décadas un obstáculo importante para poder desarrollar un debate público sobre Romero, que permitiera cuestionar las afirmaciones centrales sobre las que se basaban las percepciones de Romero arriba mencionadas. En consecuencia, hasta la llegada de Jorge Bergoglio al pontificado vaticano en 2013, cada una de los sectores de la Iglesia salvadoreña continuó alimentando su propia visión sin necesidad de someter sus creencias a un análisis histórico riguroso.

\section{La experiencia de los diálogos intergeneracionales en las parroquias de la Arquidiócesis de San Salvador}

La extensión del impacto de la política de silencio y olvido en el desconocimiento generalizado por los miembros de las comunidades católicas salvadoreñas que no estuvieron expuestos al conflicto armado sobre la dura represión militar y policial a la que fueron sometidos quienes formaron parte de sus mismas comunidades, quedó de manifiesto en las dos reuniones que la Oficina de Tutela de Derechos Humanos del Arzobispado de San Salvador llevó a cabo en julio de 2018 con dos de las vicarías de la Arquidiócesis, y a las que tuve la oportunidad de asistir.

Durante estos encuentros, a los que acudieron cerca de 500 integrantes de una veintena de parroquias, los participantes se agruparon por comunidades parroquiales, con el fin de que abordasen los recuerdos que conservaban sobre el impacto que tuvo el conflicto armado en su dinámica de funcionamiento. Si bien en un primer momento hubo cierta reticencia a abordar este tema por parte de la generación que había padecido el conflicto, conforme se fueron dando las primeras intervenciones se superaron las barreras invisibles del silencio y el olvido, para finalizar, al cabo de tres horas, con una amplia presentación de las diversas experiencias de la violencia a la que estuvieron expuestos una buena parte de quienes fungían en aquel entonces como agentes de pastoral, catequistas, lectores de palabra, religiosos y sacerdotes.

personalmente el 28 de febrero al Padre Alfonso Navarro (que sería asesinado meses después en la colonia Miramonte) a oficiar una misa con los manifestantes, Romero tuvo constancia de primera mano de la violencia que se vivió durante la carga que la policía y el ejército, con el apoyo de francotiradores, lanzaron al acabar la misa para desalojar a los manifestantes, lo que provocó decenas de muertos. Ante esta situación, Romero solicitó públicamente a las autoridades competentes que investigaran lo sucedido y se negó a participar en cualquier acto oficial hasta que no se conociese la verdad, lo que le llevó a ausentarse del acto de investidura del nuevo presidente electo, el General Humberto Romero. 
Muchos de los intervinientes explicaron que durante el conflicto armado llevaban las Biblias escondidas porque portar una Biblia era tan peligroso, o más, que llevar un arma de fuego en caso de ser detenido e inspeccionado por un retén del ejército o de la policía. Al escuchar estos relatos, los jóvenes menores de veinticinco años mostraban una gran sorpresa, porque por primera vez en su vida se les hacía partícipes de historias como las que allí estaban narrando sus propios hermanos de comunidad parroquial. Sin embargo, en lugar de levantarse ofendidos por el contenido de las mismas, o por haber sido privados de su conocimiento durante tantos años, permanecieron escuchando atentamente a sus mayores hasta que las reuniones finalizaron.

De esta manera, los diálogos intergeneracionales permitieron constatar que el miedo que se pasó durante el conflicto armado, y la política de silencio y olvido impuesta desde la institucionalidad a partir de la Ley de Amnistía de 1993, han sido tan efectivas, que veinticinco años después toda una generación de salvadoreños no sólo desconoce la historia de su país, sino que jamás ha escuchado las historias de vida de los hermanos mayores de sus propias comunidades parroquiales, porque han sido condenadas a permanecer fuera de la memoria comunitaria en el baúl de lo innombrable.

Los diálogos intergeneracionales también pusieron de manifiesto que el sistema educativo y los contenidos de las catequesis de confirmación no sólo no han sido ajenos a esta situación, sino que han sido instrumentos muy útiles a la hora de promover la desmemoria que caracteriza hoy a la sociedad salvadoreña, en general, y a sus comunidades eclesiales, en particular. Así, según explicaban sus jóvenes participantes, los programas de ciencias sociales e historia impartidos en el bachillerato apenas si dedican una o dos clases a abordar el conflicto armado salvadoreño, sin entrar en sus causas y consecuencias, y limitando su exposición a una serie de fechas emblemáticas en su desarrollo.

Del mismo modo, las catequesis de confirmación, que en principio deberían tener un fuerte arraigo en las comunidades parroquiales a las que se van a incorporar los confirmandos, obvian por completo todo lo relativo al impacto que el conflicto armado tuvo en las mismas y al sacrificio, con frecuencia martirial, que fue voluntariamente asumido por muchos de sus integrantes en nombre del modelo de vida propuesto por Jesús de Nazaret en las Bienaventuranzas, y con la esperanza de que después de la tortura y el ajusticiamiento de la Pascua llegaría la alegría de la Resurrección. Esta situación, llama más la atención si tenemos en cuenta que, como el Consejo Episcopal Latinoamericano subraya (2005), las espiritualidades pascual y martirial son dos de las características centrales de su propuesta de espiritualidad juvenil para América Latina. 
Pero al mismo tiempo, la experiencia de los diálogos intergeneracionales también ha mostrado una gran potencialidad como herramienta para exponer y superar el impacto de la política de silencio y olvido desde las propias comunidades parroquiales afectadas, reavivando con ello la esperanza de los hermanos que sufrieron la violencia frente al olvido al que han sido condenados durante décadas por la institucionalidad estatal y católica, y promoviendo así que, sin olvidar, puedan reconstruirse del daño sufrido (Benjamin, 2005; Adorno, 2006; Levi, 2005; Berón Ospina, 2019).

Además, al compartir las vivencias personales de la violencia con el resto de integrantes de la comunidad parroquial, en particular con los más jóvenes, se satisface el derecho de la comunidad, en tanto que microsociedad, a conocer las circunstancias en que se produjeron las violaciones graves de Derechos Humanos que sufrieron, lo que promueve que sean tenidas en consideración a la hora de forjar el legado de la comunidad, favorece la adopción de medidas de prevención frente a posibles intentos de revisionismo histórico y permite que se tomen los pasos necesarios al interior de la comunidad para evitar su repetición (Corte IDH, casos Barrios Altos (2001), Tibi (2004) y Comunidad Moiwana (2005); Com. IDH, casos Parada Cea y otros (1999), Ignacio Ellacuría y otros (1999) y Monseñor Oscar Romero (2000); Szablewska \& Bachmann, 2015).

\section{Conclusiones}

La política de silencio y olvido que ha sido adoptada en El Salvador tras la Ley de Amnistía de 1993 ha fomentado un desconocimiento general en la sociedad salvadoreña, particularmente en los jóvenes menores de veinticinco años, sobre las causas y consecuencias del conflicto armado y las graves violaciones de Derechos Humanos que ocurrieron durante el mismo, lo que, como la Corte IDH y la Com. IDH han afirmado, incluyendo en varios casos relativos a El Salvador (Parada Cea et al., 1999; Ignacio Ellacuría et al., 1999; Monseñor Oscar Romero, 2000), atenta contra las dimensiones individual y colectiva del derecho a la verdad, así como contra el derecho de las víctimas a la reparación, impidiendo la realización de la garantía de no repetición como objetivo central de todo proceso de justicia de transición exitoso (Galain Palermo, 2016).

Las comunidades parroquiales de la Iglesia salvadoreña no son ajenas a esta situación porque, como han puesto de manifiesto los diálogos intergeneracionales promovidos desde la Oficina de Tutela de Derechos Humanos del Arzobispado de San Salvador en julio de 2018, sus integrantes más jóvenes desconocen completamente el grado de persecución al que sus hermanos de comunidad fueron sometidos durante el conflicto armado por las fuerzas militares y policiales. 
Como muestra la controversia existente, al menos hasta 2013, entre diversos sectores de la Iglesia salvadoreña sobre la figura de Óscar Arnulfo Romero, o el debate sobre la presunta tendencia izquierdista de reconocidos dirigentes del Partido Conservador de Colombia que fueron miembros de la Comisión de la Verdad de El Salvador, el desconocimiento general provocado por la política de silencio y olvido en la sociedad y en las comunidades parroquiales salvadoreñas, impide que los graves crímenes internacionales cometidos en El Salvador sean tenidos en cuenta a la hora de labrar su legado, ofrece un caldo de cultivo favorable a las iniciativas de revisionismo histórico e impide que se puedan adoptar las medidas necesarias para evitar su repetición.

Frente a esta situación, los diálogos parroquiales intergeneracionales celebrados en 2018 en la Arquidiócesis de San Salvador han mostrado su capacidad para exponer y superar el impacto de la política del silencio y el olvido desde las propias comunidades parroquiales afectadas. Por ello, se presentan como una herramienta adecuada para reavivar la esperanza entre quienes sufrieron la violencia y para satisfacer las dimensiones individual, colectiva y reparatoria del derecho a la verdad que corresponde a las víctimas, a sus comunidades parroquiales y a la sociedad salvadoreña en su conjunto. Queda ahora por ver si el Arzobispado de San Salvador decide apoyar realmente esta iniciativa mediante su inclusión en los planes pastorales de la Arquidiócesis para los próximos años.

\section{Referencias}

Adorno, T. (2006). Minima Moralia. Madrid: Akal.

Benjamin, W. (2005). Tesis sobre la historia y otros fragmentos. Mexico: Contrahistoria.

Berón Ospina, A. A. (2019). La Memoria como una Propuesta de Justicia. En E. A. López, A. Niño Castro, \& L. Tovar González (eds.) (2019). Claves de la Justicia desde América Latina, Colección Perspectivas Iberoamericanas sobre la Justicia Vol. 6, (pp. 333-342. Valencia: Tirant lo Blanch, Instituto Ibero-Americano de La Haya para la Paz, los Derechos Humanos y la Justicia Internacional \& Instituto Joaquín Herrera Flores.

Brockman, S. J. (1985). La palabra queda. Vida de Monseñor Òscar A. Romero. El Salvador: UCA Editores.

Cardenal, R. (2015). Historia de una esperanza: vida de Rutilio Grande (4 edición). San Salvador: UCA Editores. 
Cavada, M. (2005). Monseñor Romero, Su vida, su testimonio y su palabra (4a ed.). San Salvador: Imprenta Criterio y Fundación Monseñor Romero.

Comisión de la Verdad para el El Salvador. (1993). De la esperanza a la locura: la Guerra de 12 años en El Salvador. Informe de la Comisión de la Verdad para El Salvador.

Comisión Interamericana de Derechos Humanos. (1999). Caso Parada Cea y otros c. El Salvador. Informe Núm. 1/99, 27 de enero de 1999.

Comisión Interamericana de Derechos Humanos. (1999). Caso Ignacio Ellacuria y otros c. El Salvador. Informe Num. 136/99.

Comisión Interamericana de Derechos Humanos. (1999). Caso Monseñor Oscar Arnulfo Romero y Galdamez c. El Salvador. Informe Núm. 37/00, 13 de abril de 2000.

Consejo Episcopal Latinoamericano. (2005). Civilización del amor: tarea y esperanza. Orientaciones para una Pastoral Juvenil Latinoamericana. Colección Documentos CELAM. Núm. 161.

Corte Interamericana de Derechos Humanos. (1988). Caso Velasquez Rodriguez c. Honduras. Fondo. 29 de julio de 1988.

Corte Interamericana de Derechos Humanos. (2001). Caso Barrios Altos c. Perú. Fondo. Marzo 14, 2001.

Corte Interamericana de Derechos Humanos (2004). Caso Tibi c. Ecuador. Objeciones preliminares, meritorio, reparaciones y costas, 7 de septiembre de 2004.

Corte Interamericana de Derechos Humanos (2005). Caso Moiwana c. Suriname. Objeciones preliminares, fondo, reparación y costas, 15 de junio de 2005.

Delgado Acevedo, J. (1986). Óscar A. Romero. Biografía. Madrid: Ediciones Paulinas.

Europa Press (2015) El Vaticano reconoce que hubo campaña de desprestigio contra Oscar Romero y revela que Benedicto XVI desbloqueó la causa. Recuperado de https://www.europapress.es/sociedad/noticia-vaticano-reconoce-hubo-campana-desprestigio-contra-oscar-romero-revela-benedicto-xvi-desbloqueo-causa-20150204150533.html

Galain Palermo, P. (2016). A Modo de Conclusión. En P. Galain (ed.). ¿Justicia de transición? Mecanismos políticos y jurídicos para la elaboración del pasado, (pp. 399-415). Valencia: Tirant Lo Blanch. 
Gordon, Sara (1989). Crisis Política y Guerra en El Salvador (México D.C.: Siglo XXI). Recuperado de https://books.google.com.co/books?id=Bb4_E_9roSYC\&pg=PA206\&lpg=PA206\&dq=F.A.R.O.+prensa $+1977++$ El+salvador\&source $=-$ bl\&ots=prQ3kMwM7m\&sig=ACfU3U1gUGNS28CnP6_sKrXY0HYr24xLsg\&hl=en\&sa=X\&ved=2ahUKEwjDzZa3vcHgAhWs1FkKHca1AZMQ6AEwDXoECAUQAQ\#v=onepage\&q=F.A.R.O.\%20prensa\%201977\%20\%20El\%20 salvador\&f=true

Ibáñez, J. E. (2014). Justicia transicional y Comisiones de la verdad.: Madrid: Instituto Berg.

Levi, P. (2005). Los hundidos y los salvados. Barcelona: Aleph.

Lima, L. (2018). Canonización de Monseñor Romero: por qué El Salvador no ha juzgado en casi 40 años a los asesinos del "santo de América". Recuperado de https://www.bbc.com/mundo/noticias-45817310.

López Vigil, M. (1993). Piezas para un retrato (1ªed.). San Salvador: UCA Editores. Machado, A. (1971), Poesías Completas: Proverbios y Cantares, Núm. LIII. Espasa-Calpé. Mata, S. (2015). Monseñor Óscar Romero. Pasión por la Iglesia. Madrid: Ediciones Palabra.

Morozzo Della Rocca, R. (2010), Monseñor Romero. Vida, pasión y muerte en El Salvador. Salamanca: Ediciones Sígueme.

Nietzsche, F. (2015). Consideraciones intempestivas. Barcelona: Alianza.

Ordaz, P. (2015). Roma admite que las críticas contra Romero frenaron su beatificación. Recuperado de https://elpais.com/internacional/2015/02/04/actualidad/1423089630_451905.html.

Romero, O. A. (1989). Monseñor Oscar Arnulfo Romero: su Diario. San Salvador: Imprenta Criterio.

Romero, O. A. (2005). Homilías. Vol. VI. San Salvador: Universidad Centroameriana - UCA.

Secretariado Social Interdiocesano. (1977). Persecución de la Iglesia en El Salvador. El Salvador: Publicaciones del Secretariado Social Interdiocesano, El Salvador.

Szablewska, N., \& Bachmann S. D. (eds.). (2015). Current issues in Transitional Justice: towards a more holistic approach. Springer. 
Tamayo, J. J. (coord.). (2015). San Romero de América, Mártir de la Justicia. Valencia: Tirant lo Blanch.

Tribunal Europeo de Derechos Humanos. (2004). Caso Ipek c. Turquía. Sentencia de 17 de febrero de 2004.

Tribunal Europeo de Derechos Humanos. (2009). Caso Varnava y otros c. Turquía. Sentencia, 18 de septiembre de 2009. 